\title{
Шапсугова М.Д.
}

Старший научный сотрудник сектора предпринимательского и корпоративного права, Институт государства и права РАН, кандидат юридических наук, доцент

\section{О НАУЧНОМ ПОДХОДЕ К ЮРИДИЧЕСКИМ ИССЛЕДОВАНИЯМ ПАНДЕМИИ КОРОНАВИРУСНОЙ ИНФЕКЦИИ}

\section{Аннотация}

В связи с возросшей актуальностью исследований пандемии в юридической науке наблюдается значительный прирост новых знаний в данной области. Вместе с тем, научное осмысление явления пандемии в юридических исследованиях требует сугубо научного подхода.

Учитывая изложенное в статье исследуются цели, задачи правовых научных исследований влияния пандемии на правовую систему, предлагаются возможные методы исследования и ожидаемыле научные результаты.

Due to the increased relevance of pandemic research in legal science, there has been a significant increase in new knowledge in this area. Simultaneously, a scientific understanding of the pandemic phenomenon in legal research requires a purely scientific approach.

The article examines the goals and objectives of legal, scientific research on the impact of a pandemic on the legal system, suggests possible research methods and expected scientific results.

Ключевые слова: пандемия, научные исследования, коронавирусная инфекция, чрезвычайное реагирование, адаптация правовой системы, кризис, права человека, невозможность исполнения обязательства, феноменологический подход, феноменология, баланс публичных и частных интересов

Keywords: pandemic, COVID 19, scientific research, coronavirus infection, emergency response, adaptation of the legal system, crisis, human rights, impossibility to fulfill an obligation, phenomenological approach, phenomenology, balance of public and private interests

Цели и задачи научных исследований в анализируемой сфере служат реализации фундаментальной научной задачи разработки стратегии ответа на пандемию коронавируса как большого вызова социально-экономическим отношениям.

Их целью является выработка и научная оценка правовых мер принимаемых на основных стадиях реагирования на пандемию как большой вызов: 1)чрезвычайное реагирование, 2) адаптация правовой системы к социально-экономическим потребностям общества в период пандемии и 3) выход из кризиса, вызванного пандемией коронавирусной инфекции с постепенным снятием установленных ограничений и мер поддержки.

Приоритетными задачами исследований являются следующие:

1. исследование прямых и косвенных методов государственного регулирования экономики в условиях пандемии коронавируса;

2. определение тенденции правового регулирования, возникших в период пандемии, которые закрепятся в законодательстве на долгосрочную перспективу, исследование смещения баланса публичных и частных интересов в период пандемии: необходимость обеспечения интересов здравоохранения и ограничения прав на передвижения;

3. анализ вводимых ограничений на предмет угрозы нарушения прав человека в условиях пандемии учитывая принципы определения пределов, сроков и соразмерности вводимых ограничений; 
4. установление наличие законной цели при ограничении прав, соразмерности ограничений прав, определение сроков и пределов ограничительных мер, и мер поддержки, принимаемых на государственном уровне ;

5. анализ опыт иностранных государств в правовом регулировании социальноэкономических отношений в условиях пандемии;

6. исследование имеющихся правовых инструментов реагирования на проявления пандемии (режим повышенной готовности, карантин, и др понятия, требующие переосмысления в условиях пандемии на предмет их влияния на гражданский оборот и исполнение предпринимательских обязательств);

7. пересмотр существующих правовых институтов на предмет их адаптивности к новым условиям функционирования;

8. анализ принимаемых правовых мер на предмет экономических и правовых последствий;

9. анализ необходимости кодификации и унификации правового регулирования по вопросам пандемии;

10. разработка правовых основ использования искусственного интеллекта и цифровых платформ для борьбы с пандемией (телемедицина, отслеживание перемещений, определение контактов) в контексте необходимости использования персональных данных;

11. исследование правовых ограничений, препятствующих дистанционной трудовой деятельности, дистанционному оказанию государственных услуг, дистанционному осуществлению правосудия, оказанию нотариальных услуг, оказанию дистанционной медицинской помощи;

12. оценка конкурентоспособности российской правовой системы в условиях пандемии;

13. Выработка предложений по разработке правовых меры по восстановлению экономики в период выхода из кризиса, вызванного пандемией коронавирусной инфекции.

При исследовании принципиально новых вызовов обществу в связи с пандемией коронавируса необходимо использование феноменологического подхода, который позволит взглянуть на экономические и правовые последствия пандемии коронавирусной инфекции с позиции «чистого наблюдателя». Применение феноменологической методологии к научному осмыслению действительности имеет принципиальное значение как в силу феноменологического характера самого явления пандемии коронавируса 2020 года, так и в целом в период глобальных социально-экономических кризисов, войн, поскольку они знаменуют собой обнуление действовавших общественных договоров, коренные трансформации социальных, экономических, политических институтов, влекут пересмотр системы общественных ценностей в общемировом масштабе. Таким образом, феноменологический метод позволит выявить принципиально новые тенденции правового регулирования текущих и перспективных социально-экономических процессов, направления глобальных изменений и их правового обеспечения.

В то же время, применяя принцип «не умножать сущности без необходимости», не следует отбрасывать накопившийся в осмыслении и правовом регулировании отдельных институтов , таких как невозможность исполнения обязательства и непреодолимая сила, крайняя необходимость, режим повышенной готовности, опыт, который может быть имплементирован к сегодняшней актуальной проблематике при помощи догматического метода и двух его направлений - легального и доктринального.

Диалектически метод необходим в поиске баланса публичного и частного интереса, анализе конкуренции прав человека в период пандемии.

Исследование уникального, созданного в процессе борьбы с эпидемией коронавируса правового опыта зарубежных государств потребует применения сравнительно-правового метода. При помощи исторического метода может быть 
проанализирован опыт правового регулирования в предшествующих войнах и пандемиях холеры, испанки и т.д.

Категориальный метод необходим для осмысления таких ставших сегодня актуальными понятий как «карантин», «режим повышенной готовности», «крайняя необходимость», «невозможность исполнения», непреодолимая сила» и т.д.

Метод моделирования и социально-правового эксперимента будет использован для оценки правовых и социально-экономических последствий кризиса вызванного пандемией коронавирусной инфекции, а также выработки предложений по совершенствованию законодательства.

В ходе исследования предполагается применение экономического анализа права в период пандемии коронавируса. $\mathrm{C}$ использованием позитивного подхода будет определяться соответствие текущего регулирования экономико-социальным реалиям, использование позитивного подхода позволит предложить рекомендации по совершенствованию законодательства.

В процессе исследования влияния пандемии на развитие правовых систем ожидается разработка комплексного междисциплинарного подхода к правовому регулированию социально-экономических отношений в условиях кризиса. Проведенный в ходе исследований анализ принятых государством антикризисных мер на предмет их влияния на социально-экономические отношения в краткосрочном и долгосрочном периоде позволит дать оценку потенциала социально-экономических трансформаций как ответа на большой вызов.

Перечисленное позволит выявить наиболее эффективные формы и методы правового регулирования в период пандемии.

Ожидаемый научный результат обусловлен поставленной фундаментальной научной задачей и достижением целей и задач исследования.

Экономический кризис 2008 года не привел к структурным изменениям в экономике, экономический кризис вызванный пандемией коронавируса в силу особенностей его протекания их неизбежно повлечет.

Поскольку в период прохождения обществом острых социально-экономических кризисов происходит обнуление общественных договоренностей, возникает уникальная возможность провести в структуре российской экономики глобальные трансформации, которые не были осуществлены до этого времени.

Поиск нового баланса публичных и частных интересов требует новых походов к осмыслению пределов допустимого ограничения частного интереса в интересах всех, и в конечном счете интересах каждого. В чрезвычайных условиях как никогда общественное благо становится интересом каждого и и принцип солидарности получает новое звучание.

Сегодняшняя пандемия привела к остановке производств, что ведет к падению доходов, безработице, нарушениям трудовых прав, и в конечном итоге к экономическому кризису.

Так, самоизоляция, социальное дистанцирование неизбежно повлекут цифровизацию всех областей жизнедеятельности человека ускоренными темпами. Прогресс в сфере дистанционных технологий приведет к развитию альтернативных способов осуществления прав гражданами - в цифровой среде пространств доверия, с применением методов идентификации. Эти процессы актуализируют вопросы их правовой обеспеченности.

Научная новизна проекта заключается в формировании научно-обоснованного подхода к стратегии государства в борьбе с глобальным социально-экономическим кризисом, вызванным пандемией коронавируса. Впервые дается комплексная экономикоправовая оценка предпринятым государствами мерам, потенциалу имеющегося правового регулирования, предпринятым изменениям в законодательстве с позиций баланса экономического эффекта, прав человека, безопасности общества и в целом публичных и частных интересов. 
В силу особенностей общественных отношений их правовое регулирование может как способствовать их развитию так и препятствовать ему. Обслуживая экономические потребности общества в период кризиса, право выступает как универсальный регулятор общественных отношений. Впервые в проекте будет дана оценка правовым и экономическим последствиям принятых мер по следующим направлениям.

1. Трансформация трудовых отношений: кризис обострил проблему правового регулирования дистанционного труда, социальной защиты самозанятого населения, проблему защиты прав работников в период пандемии.

2. Трансформация прав человека, формирование нового поколения прав человека цифровых прав.

3. Пересмотр оснований, пределов, сроков ограничений прав человека.

4. Проблема защиты персональных данных: использование данных интернетпровайдеров и мобильных операторов для отслеживания перемещений лиц находящихся на карантине и самоизоляции, вопросы целевого использования таких данных, в том числе после окончания пандемии.

5. Ограничение свободы перемещений.

6. Проблемы правового регулирования принудительного лечения.

7. Ограничение свободы информации в период пандемии, обусловленное необходимостью борьбы с фейковыми новостями и паникой: его пределы.

8. Ограничение права на осуществление предпринимательской деятельности: принудительное закрытие предприятий и организаций . Меры поддержки бизнеса, в том числе малого и среднего, помощь организациям в организации работы в условиях пандемии.

9. Развитие методов мягкого права и различных рекомендаций издаваемых государствами с точки зрения последствий для исполнения обязательств предпринимателями.

10. Исследование специальных режимов карантина, самоизоляции, повышенной готовности, чрезвычайной ситуации.

11. Кризис договорных отношений: анализ способов прекращения обязательств на основании издания органами власти актов, невозможности исполнения обязательств, исследование пандемии на предмет ее действия как непреодолимой силы. Юридическая и физическая невозможность исполнения обязательств.

12. Необходимость введение процедур упрощенного банкротства граждан в связи с ухудшением финансового положения граждан

13. Пересмотр и снятие антимонопольных ограничений в отдельных отраслях экономики, в особенности в сфере лекарств, медицинского оборудования.

14. Ускоренное развитие правововых основ цифровизации, электронной коммерции, искусственного интеллекта.

15. Обеспечение защиты прав и свобод в условиях карантина, права на доступ к правосудию в условиях ограничений.

16. Организация экономических процессов и обслуживания населения после карантина.

17. Необходимость выработки общих межгосударственных подходов к обеспечению соблюдения прав человека в условиях пандемии.

Прикладная значимость научных исследований выражается в формировании научно обоснованных предложений по изменению действующего законодательства с учетом диктуемых кризисом направлений трансформации общественных отношений.

Принятые меры должны обеспечивать плавный выход из чрезвычайного регулирования и восстановление экономики. 